\title{
Hydrogen retention in ITER relevant mixed material layers
}

\author{
K. Sugiyama ${ }^{1}$, K. Krieger ${ }^{1}$, C.P. Lungu ${ }^{2}$, J.Roth $^{1}$ \\ ${ }^{1}$ Max-Planck-Institut für Plasmaphysik, EURATOM Association, Boltzmannstrasse 2, \\ D-85748 Garching, Germany \\ ${ }^{2}$ National Institute for Laser, Plasma and Radiation Physics of Romania, Association \\ EURATOM-MEdC, Bucharest, Romania
}

\begin{abstract}
$\mathrm{D}$ retention in mixed layers of ITER first wall materials, i.e. $\mathrm{Be}_{2} \mathrm{C}$ (prepared by annealing C film on Be substrate sample at $773 \mathrm{~K}$ ), $\mathrm{Be}_{12} \mathrm{~W}$ (by annealing $\mathrm{W}$ film on Be substrate at $1073 \mathrm{~K}$ ) and tungsten carbide (by annealing W film on graphite substrate annealed at 1373K) was investigated under controlled laboratory conditions. D retention in $\mathrm{Be}_{2} \mathrm{C}$ and $\mathrm{Be}_{12} \mathrm{~W}$ layers was similar to that of $\mathrm{Be}$ rather than that of graphite or $\mathrm{W}$ respectively, while $\mathrm{D}$ retention in tungsten carbide layers was similar to that of polycrystalline $\mathrm{W}$ rather than that of graphite. The fluence dependence of the retained D fraction in each mixed layer showed no clear saturation in the experimentally accessible implantation fluence range $\left(<4.0 \times 10^{23} \mathrm{D} / \mathrm{m}^{2}\right)$, and increased with incident fluence as $\sim \Phi^{0.2}$ in $\mathrm{Be}_{2} \mathrm{C}, \mathrm{Be}_{12} \mathrm{~W}$ and $\sim \Phi^{0.5}$ in tungsten carbide.
\end{abstract}

PSI Keywords: Deuterium inventory, First wall, Beryllium, Carbide

JNM keywords: B0100, C0100, D0500, F0400, H0400, P0500

PACS. No. 52.40.Hf (Plasma-wall interactions; boundary layer effects; plasma sheaths)

*Corresponding author:

Kazuyoshi Sugiyama

Max-Planck-Institut für Plasmaphysik, EURATOM Association

Boltzmannstrasse 2, D-85748 Garching, Germany

TEL: +49-(0)89-3299-1492

FAX: +49-(0)89-3299-1212

E-mail: kazuyoshi.sugiyama@ipp.mpg.de 


\section{Introduction}

The current design of ITER plasma facing components envisages using several different armour materials depending on the operational requirements, i.e. beryllium $(\mathrm{Be})$ is the primary candidate for the first wall material, whereas tungsten (W) is chosen for the divertor armour, except for the area around the strike points where carbon fibre composite (CFC) is designated as armor material [1]. Based on observations in present fusion devices, it is expected that the wall material will be eroded due to the interaction with plasma particles and subsequently deposited on other material surfaces. This leads to the formation of mixed material layers on the wall surface.

Material mixing can change not only the thermomechanical properties, such as thermal conductivity or melting point, but also fuel retention properties of the plasma facing wall. Fuel retention influences the hydrogen recycling on the plasma facing surface and the tritium inventory in the vacuum vessel. In ITER, for safety reasons, periodic tritium removal will be required before the in-vessel tritium inventory reaches its administrative limit [2], meaning that tritium retention rate strongly affects ITER operation program in the D-T phase.

From these considerations, hydrogen uptake and retention in mixed material systems is an important issue for reliable extrapolation of in-vessel tritium retention in ITER. Although various investigations have been done to clarify the hydrogen retention properties of each pure material, there are only a few available data for mixed materials at present [3-7]. In this study, representative mixed material layers of $\mathrm{Be}, \mathrm{C}$ and $\mathrm{W}$ were prepared, and hydrogen retention in those layers was investigated under controlled laboratory conditions. The result is compared with the data of pure materials, and its impact for in-vessel tritium inventory is discussed.

\section{Experimental}

\subsection{Sample preparation}


Mixed layers were fabricated by thermally treating the different material combinations of film-substrate samples. The detailed procedure is as follows: Polycrystalline Be with $99.4 \%$ purity (Goodfellow Co. Ltd.) and EK98 fine grain graphite were prepared as substrate. Each substrate was cut with a dimension of $12 \times 15 \times 1.0 \mathrm{~mm}^{3}$, and the surface for film deposition was polished to mirror-finish. $\mathrm{C}$ and $\mathrm{W}$ films were produced by means of magnetron sputter deposition without biasing and without intentional heating. The initial film thickness was 200 $300 \mathrm{~nm}$. After film deposition, samples were annealed at a certain temperature / duration under a pressure of $\sim 10^{-8}$ mbar. The set of samples produced by this procedure is summarized in table 1 . In each case, the substrate is the lighter element, from which one expects that the film will be transformed completely to a compound with the substrate element by diffusion of the substrate element into the deposited film at elevated temperature.

The thickness and composition of each layer after annealing were analyzed by Rutherford Backscattering Spectrometry (RBS) as shown in Fig. 1. In RBS, the amount of each element is given as areal density $\left[\right.$ atoms $\left./ \mathrm{cm}^{2}\right]$, hence the layer thickness was determined by calculating from the areal density of each element and theoretical density of each pure material (Be: 1.8 $\left.\mathrm{g} / \mathrm{cm}^{3}, \mathrm{C}: 2.2 \mathrm{~g} / \mathrm{cm}^{3}, \mathrm{~W}: 19.3 \mathrm{~g} / \mathrm{cm}^{3}\right)$. The C layer on Be sample annealed at $773 \mathrm{~K}$ developed to a resulting mixed layer with a $\mathrm{Be} / \mathrm{C}$ ratio of $2: 1$, which indicated the formation of a $\mathrm{Be}_{2} \mathrm{C}$ phase. In this case, however, some cracks were found on the layer, which is probably due to the lower ductility of $\mathrm{Be}_{2} \mathrm{C}$ compared to that of $\mathrm{Be}$ which also has a relatively high thermal expansion coefficient $\left(11.5 \sim 16.5 \times 10^{-6} \mathrm{~K}^{-1}(300 \sim 800 \mathrm{~K})\right)$. W on Be substrates showed $\mathrm{Be}_{12} \mathrm{~W}$ formation after annealing at $1073 \mathrm{~K}$, which was confirmed by the observed stoichiometric number of the final mixed layer ( $\mathrm{W}$ concentration $\sim 8$ at. $\%$, by RBS). W on graphite samples had a W/C ratio of $4: 3$ in the resulting mixed layer after annealing at $1373 \mathrm{~K}$. According to XRD analysis, there were no $\mathrm{W}$ peaks, but mono-tungsten carbide (WC) and di-tungsten carbide $\left(\mathrm{W}_{2} \mathrm{C}\right)$ peaks were observed. 


\subsection{D implantation and post mortem analysis}

Deuterium implantation into prepared samples was performed in the High Current Ion Source at IPP-Garching. The energy of the $\mathrm{D}$ ion beam was $600 \mathrm{eV} \mathrm{D}_{3}^{+}(200 \mathrm{eV} / \mathrm{D})$, which is a characteristic value derived from typical boundary plasma temperatures including sheath acceleration. The angle of incidence was normal to the target surface. Implantation was carried out at room temperature without intentional heating / cooling (the sample itself could be heated up to $\sim 100{ }^{\circ} \mathrm{C}$ because of the ion bombardment). The incident flux was $\sim 3 \times 10^{19} \mathrm{D} / \mathrm{m}^{2} \mathrm{~s}$.

After reaching predefined values of fluence (up to $\sim 4 \times 10^{23} \mathrm{D} / \mathrm{m}^{2}$ ), the amount of D retained in the sample was measured by nuclear reaction analysis (NRA). The D concentration in the near surface layer $(<1 \mu \mathrm{m})$ was measured using the $\mathrm{D}\left({ }^{3} \mathrm{He}, \alpha\right)$ p nuclear reaction with a ${ }^{3} \mathrm{He}$ energy of $0.69 \mathrm{MeV}$. The $\alpha$ particles produced by the nuclear reaction were energy-analyzed with a small-angle surface barrier detector at a laboratory angle of $102^{\circ}$. The obtained $\alpha$ spectrum was transformed to a D depth profile using the program SIMNRA [8]. The D concentration in deeper regions up to $\sim 5 \mu \mathrm{m}$ was analyzed using the same nuclear reaction $\mathrm{D}\left({ }^{3} \mathrm{He}, \mathrm{p}\right){ }^{4} \mathrm{He}$, however, in this case detecting the emitted protons. In this case, the ${ }^{3} \mathrm{He}$ energy was varied from $0.69 \mathrm{MeV}$ to $2.0 \mathrm{MeV}$, and the proton peaks for each ${ }^{3} \mathrm{He}$ energy were counted by a wide-angle surface barrier detector at a laboratory angle of $135^{\circ}$. For depth profile analysis, a $\mathrm{D}$ depth profile was assumed, taking into account also the near-surface depth profile obtained from the $\alpha$ spectrum. Then the proton yield of this assumed depth profile as a function of incident ${ }^{3} \mathrm{He}$ energy was calculated by SIMNRA. The form of the assumed D depth profile was then modified and iterated until the calculated proton yield curve matched the experimental curve [9]. The total amount of D retention was finally determined by integrating the D profile over the measured depth. 


\section{Results \& Discussion}

Figure 2 shows the D retained fluence in each mixed layer as a function of incident fluence (Ф) together with literature data [10-12] of each pure material.

The amount of $\mathrm{D}$ retention in $\mathrm{Be}_{2} \mathrm{C}$ increased very closely to that in pure $\mathrm{Be}$ in the fluence range below $\sim 5 \times 10^{22} \mathrm{D} / \mathrm{m}^{2}$, but became slightly higher than for pure Be at $4 \times 10^{23} \mathrm{D} / \mathrm{m}^{2}$. Depth profiles determined by NRA are summarized in Fig.3. In $\mathrm{Be}_{2} \mathrm{C}$, one observes a relatively sharp D concentration peak at the top surface $(\sim 100 \mathrm{~nm})$ with a shoulder in the near surface region $(100 \sim 300 \mathrm{~nm})$. Moreover, a relatively long tail extending into the Be substrate was found, which might be due to the cracks mentioned above. However, no significant D accumulation occurred in the Be substrate. At higher fluence values, the $\mathrm{D}$ concentration in the $\mathrm{Be}_{2} \mathrm{C}$ layer increased continuously up to the experimental fluence limit, meaning the amount of $\mathrm{D}$ retention in $\mathrm{Be}_{2} \mathrm{C}$ did not saturate while $\mathrm{D}$ retention in both pure $\mathrm{Be}$ [12-14] and graphite [15] show quasi-saturation behaviour above $\sim 10^{21} \mathrm{D} / \mathrm{m}^{2}$ incident fluence. Power-law fitting showed the fluence dependence of $\mathrm{D}$ retention in $\mathrm{Be}_{2} \mathrm{C}$ as $\sim \Phi^{0.17}$.

The behaviour of $\mathrm{D}$ retention in $\mathrm{Be}_{12} \mathrm{~W}$ was closer to that in $\mathrm{Be}$ than that in $\mathrm{W}$, which is reasonable because $\mathrm{Be}_{12} \mathrm{~W}$ consists of 92 at. $\%$ of $\mathrm{Be}$ and 8 at. $\% \mathrm{~W}$. The main difference was found in the lower incident fluence range $\left(<10^{22} \mathrm{D} / \mathrm{m}^{2}\right)$ where the amount of retained D in $\mathrm{Be}_{12} \mathrm{~W}$ was always less than $\mathrm{Be}$, indicating that $\mathrm{W}$ plays a role for the reduction of $\mathrm{D}$ retention in a Be rich layer. According to past and recent investigations, hydrogen in Be is initially trapped in ion-induced defects with relatively high trapping energy $(\sim 2 \mathrm{eV})$. Above $\sim 10^{21}$ $\mathrm{D} / \mathrm{m}^{2}$ incident fluence, however, cavities resulting from structural modification appeared, and a large fraction of retained D was accumulated in such cavities $[12-14,16]$. A similar tendency was also observed in D-implanted $\mathrm{Be}_{12} \mathrm{Ti}$ [17]. Depth profiles showed the maximum D concentration at the top surface increased from $\sim 1$ at. $\%$ to $\sim 3$ at. $\%$ between $5.0 \times 10^{20}$ and 5.3 
x $10^{21} \mathrm{D} / \mathrm{m}^{2}$ incident fluence, which likely corresponds to the cavity formation in this fluence range. At an incident fluence of $4.7 \times 10^{22} \mathrm{D} / \mathrm{m}^{2}$, the $\mathrm{D}$ concentration at the top surface was almost saturated with $\sim 4$ at.\%, and further implantation increased D concentration in the near surface layer. Although $\mathrm{D}$ accumulation in the bulk was nonnegligible in the case of polycrystalline $\mathrm{W}[10]$, bulk retention in $\mathrm{Be}_{12} \mathrm{~W}$ was clearly lower, below the detection limit. Nevertheless, no clear saturation of $\mathrm{D}$ retention was observed similarly to $\mathrm{Be}_{2} \mathrm{C}$, and the fluence dependence of retention in $\mathrm{Be}_{12} \mathrm{~W}$ was determined to $\sim \Phi^{0.21}$.

D retention in tungsten carbide showed small retention in the low fluence range and rapid increase with the incident fluence. The amount of D inventory was higher than polycrystalline W by a factor of $2 \sim 3$, which is consistent with Wang's result which showed higher D retention in tungsten carbide compared to the pure $\mathrm{W}$ by a factor of $\sim 2$ [4]. This was predictable because $\mathrm{C}$ can play some roles such as reduction of the reflection coefficient of $\mathrm{D}^{+}$or $\mathrm{D}$ trapping by $\mathrm{C}$. In fact, both Wang et al. and Kimura et al. [7] found the thermal desorption peak which was attributed to the desorption of D trapped by C. However, the amount of retained D was still order of magnitude less compared to the graphite especially in lower fluence range. In addition, while $\mathrm{D}$ in graphite reached quasi-saturation after $\sim 10^{22} \mathrm{D} / \mathrm{m}^{2}$ implantation because of low diffusivity of D in graphite, D in tungsten carbide showed no such behaviour. Consequently, although $40 \%$ of the layer constituent is carbon, the fluence dependence was closer to polycrystalline $\mathrm{W}$ rather than graphite. The depth profile showed a maximum D concentration at the top surface was almost saturated above $5.0 \times 10^{22} \mathrm{D} / \mathrm{m}^{2}$ incident fluence. On the other hand, the concentration in the near surface region continued to increase with fluence. As a consequence, no saturation was observed in the experimental fluence range, and its fluence dependence was $\sim \Phi^{0.45}$.

In ITER, beryllium carbide is likely to be formed because of $\mathrm{C}$ deposition on heated $\mathrm{Be}$ surfaces or vice versa. Since $\mathrm{Be}_{12} \mathrm{~W}$ formation needs relatively high temperatures, the reaction 
would not occur at the comparatively cool $\mathrm{W}$ surfaces in the initial configuration of the ITER plasma facing wall (the divertor target is CFC). However, it may become significant if a full W divertor is installed in the later phase of ITER. Tungsten carbide is likely to be formed on W surfaces succeeding $\mathrm{C}$ impurity deposition. Based on the results of this study, D retention in $\mathrm{Be}_{2} \mathrm{C}$ and $\mathrm{Be}_{12} \mathrm{~W}$ are expected not so far from that in pure $\mathrm{Be}$. Therefore, from the viewpoint of long-term tritium retention, the contribution of $\mathrm{Be}_{2} \mathrm{C} / \mathrm{Be}_{12} \mathrm{~W}$ would be still minor compared to CFC [18] or bulk W (in both cases, the accumulation in the bulk is significant), which is the positive aspect. Carbide formation on $\mathrm{W}$ surface might not create significant changes from $\mathrm{W}$ in terms of fuel retention. The deterioration of thermomechanical properties by alloy formation would be a much more severe effect.

\section{Summary}

$\mathrm{D}$ retention in mixed layers of respective ITER first wall materials, i.e. $\mathrm{Be}_{2} \mathrm{C}$ (prepared by annealing $\mathrm{C}$ film on Be substrate sample at $773 \mathrm{~K}$ ), $\mathrm{Be}_{12} \mathrm{~W}$ (by annealing $\mathrm{W}$ film on Be substrate sample at $1073 \mathrm{~K}$ ) and tungsten carbide (by annealing W film on carbon substrate sample at $1373 \mathrm{~K})$ was investigated under controlled laboratory conditions (200 eV D implantation at R.T.). $\mathrm{D}$ retention in $\mathrm{Be}_{2} \mathrm{C}$ and $\mathrm{Be}_{12} \mathrm{~W}$ showed behaviour close to that in $\mathrm{Be}$ rather than that in graphite or $\mathrm{W}$, while D retention in tungsten carbide layers was closer to that of polycrystalline $\mathrm{W}$ rather than that of graphite. The fluence dependence of the retained $\mathrm{D}$ fraction in each mixed layer showed no clear saturation in the experimentally accessible implantation fluence range $(<$ $4.0 \times 10^{23} \mathrm{D} / \mathrm{m}^{2}$ ), and the D retained fluence increased with the incident fluence as $\sim \Phi^{0.2}$ in $\mathrm{Be}_{2} \mathrm{C}, \mathrm{Be}_{12} \mathrm{~W}$ and $\sim \Phi^{0.5}$ in tungsten carbide. Regarding long-term fuel retention in ITER, the evolution of $\mathrm{D}$ retention in Be-related mixed materials is expected to be as that in Be, indicating it's still a minor contribution compared to those by D-retention in CFC or bulk W components, while tungsten carbide could play a similar role to $\mathrm{W}$ in terms of fuel retention. 


\section{Acknowledgement}

The authors appreciate J. Dorner, Th. Dürbeck, M. Fußeder, F. Koch and A. Weghorn for their technical assistance. This work was done under the frame of TW5 - TPP - RETMIX task agreement of the European Task Force on Plasma Wall Interactions, and partly supported by JSPS Postdoctoral Fellowship for research abroad. 


\section{References}

[1] R.Aymar, P. Babaraschi and Y. Shimomura, Plasma Phys. Control. Fusion 44 (2002) 519.

[2] G. Federici, R. A. Anderl, P. Andrew et al., J. Nucl. Mater. 266-269 (1999) 14.

[3] M. Mayer, R. Behrisch, H. Planck et al., J. Nucl. Mater. 230 (1996) 67

[4] W. Wang, V. Kh. Alimov, B. M. U. Scherzer et al., J. Nucl. Mater. 241-243 (1997) 1087

[5] V. Kh. Alimov, D. A. Komarov, J. Nucl. Mater. 313-316 (2003) 599

[6] M. J. Baldwin, K. Schmid, R. P. Doerner et al., J. Nucl. Mater. 337-339 (2005) 590

[7] H. Kimura, Y. Nishikawa, T. Nakahata et al., Fusion Eng. Des. 81 (2006) 295.

[8] M. Mayer, SIMNRA User's guide, Tech. Report IPP 9/113.

[9] V. Kh. Alimov, M. Mayer, J. Roth, Nucl. Instr. and Meth. in Phys. Res. B 234 (2005) 169.

[10] V. Kh. Alimov and J. Roth, Phys. Scripta T128 (2007) 6.

[11] O. Ogorodnikova, M. Mayer, J. Roth, J. Nucl. Mater. 313-316 (2003) 469.

[12] R. A. Anderl, R. Causey, J. W. Devis et al., J. Nucl. Mater. 273 (1999) 1.

[13] M. Reinelt and Ch. Linsmeier, Phys. Scripta T128 (2007) 111.

[14] M. Reinelt and Ch. Linsmeier, these proceedings.

[15] G. Staudenmaier, J. Roth, R. Behrisch et al., J. Nucl. Mater. 149-156 (1979) 149.

[16] V. Kh. Alimov, V. N. Chernikov, A. P. Zakharov, J. Nucl. Mater. 241-243 (1997) 1047.

[17] H. Iwakiri, K. Yasunaga, N. Yoshida et al., J. Nucl. Mater. 329-333 (2004) 880.

[18] J. Roth, V. Kh. Alimov, A.V. Golubeva et al., J. Nucl. Mater. 363-365 (2007) 822. 
Table. 1

Summary of Film-substrate combination, annealing temperature / duration and formed layer after annealing in this study

\begin{tabular}{cccc}
\hline Substrate & $\begin{array}{c}\text { Deposited layer } \\
\text { (initial thickness) }\end{array}$ & $\begin{array}{c}\text { Annealing temperature / } \\
\text { duration }\end{array}$ & Layer after aneealing (thickness) \\
\hline \hline $\mathrm{Be}$ & $\mathrm{C}(300 \mathrm{~nm})$ & $773 \mathrm{~K} / 3 \mathrm{hrs}$ & $\mathrm{Be}_{2} \mathrm{C}(\sim 900 \mathrm{~nm})$ \\
$\mathrm{Be}$ & $\mathrm{W}(200 \mathrm{~nm})$ & $1073 \mathrm{~K} / 10 \mathrm{hrs}$ & $\mathrm{Be}_{12} \mathrm{~W}(\sim 2 \mu \mathrm{m})$ \\
Graphite (EK98) & $\mathrm{W}(200 \mathrm{~nm})$ & $1373 \mathrm{~K} / 3 \mathrm{hrs}$ & $\mathrm{WC} / \mathrm{W}_{2} \mathrm{C}(\sim 300 \mathrm{~nm})$ \\
\hline
\end{tabular}




\section{Figure captions}

Fig.1:

Layer thickness and composition of (a) $\mathrm{C} / \mathrm{Be}$, (b) W/Be and (c) W/C systems after annealing determined by RBS. Note that the scale of atomic concentration of W/Be is logarithmic. In (c), the XRD spectrum is shown together with RBS results.

Fig.2:

D retained fluence of (a) $\mathrm{Be}_{2} \mathrm{C}$, (b) $\mathrm{Be}_{12} \mathrm{~W}$ and (c) $\mathrm{WC} / \mathrm{W}_{2} \mathrm{C}$ layers as a function of incident fluence together with literature data of each pure material (Be from $[10,12]$, pyrolytic graphite from $[10,15]$ and W from $[10,11])$. Error bars derive from technical error of NRA measurement.

Fig.3:

D depth profiles in (a) $\mathrm{Be}_{2} \mathrm{C}$, (b) $\mathrm{Be}_{12} \mathrm{~W}$ and (c) $\mathrm{WC} / \mathrm{W}_{2} \mathrm{C}$ layers obtained by NRA 

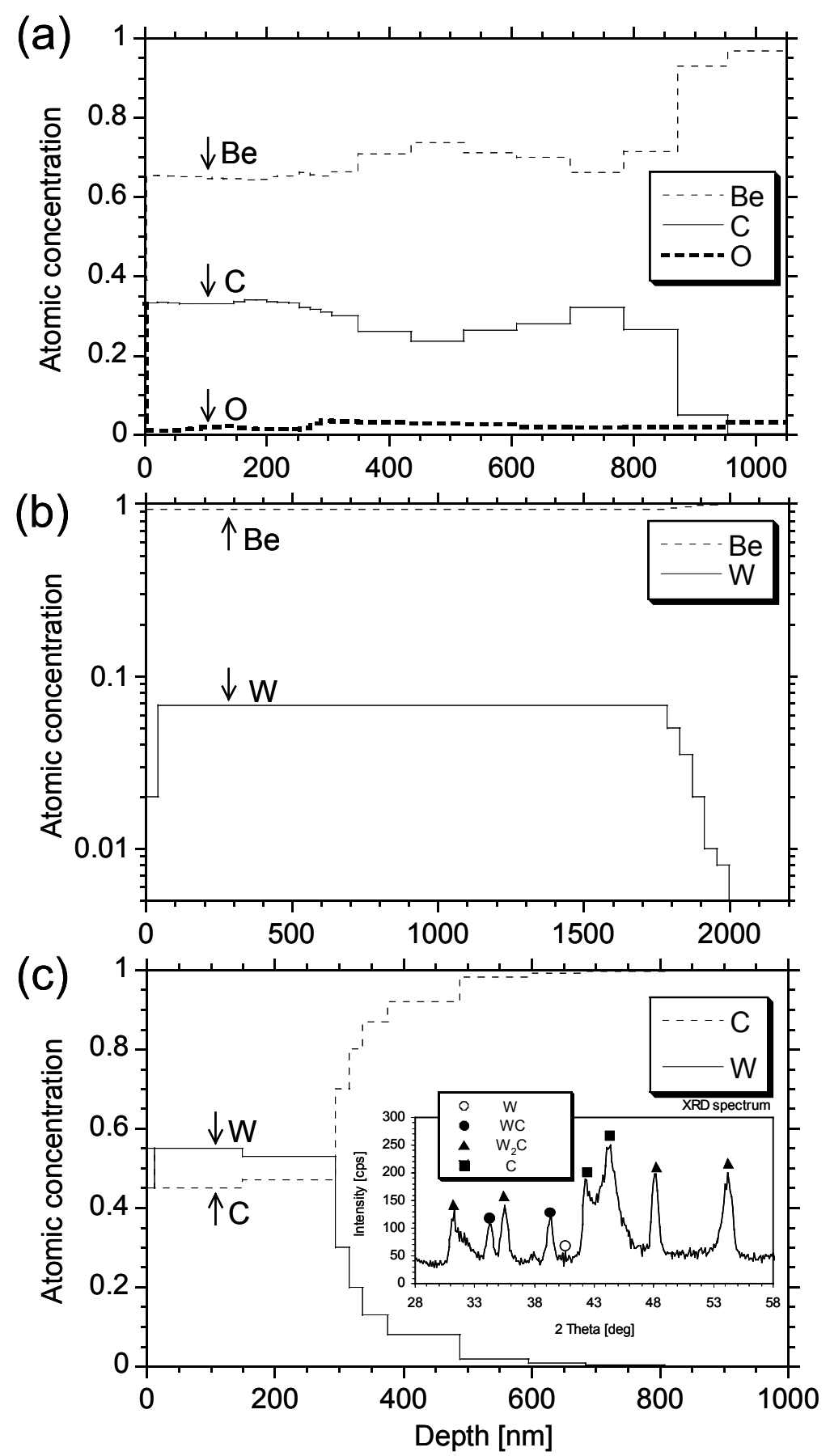

Fig.1 

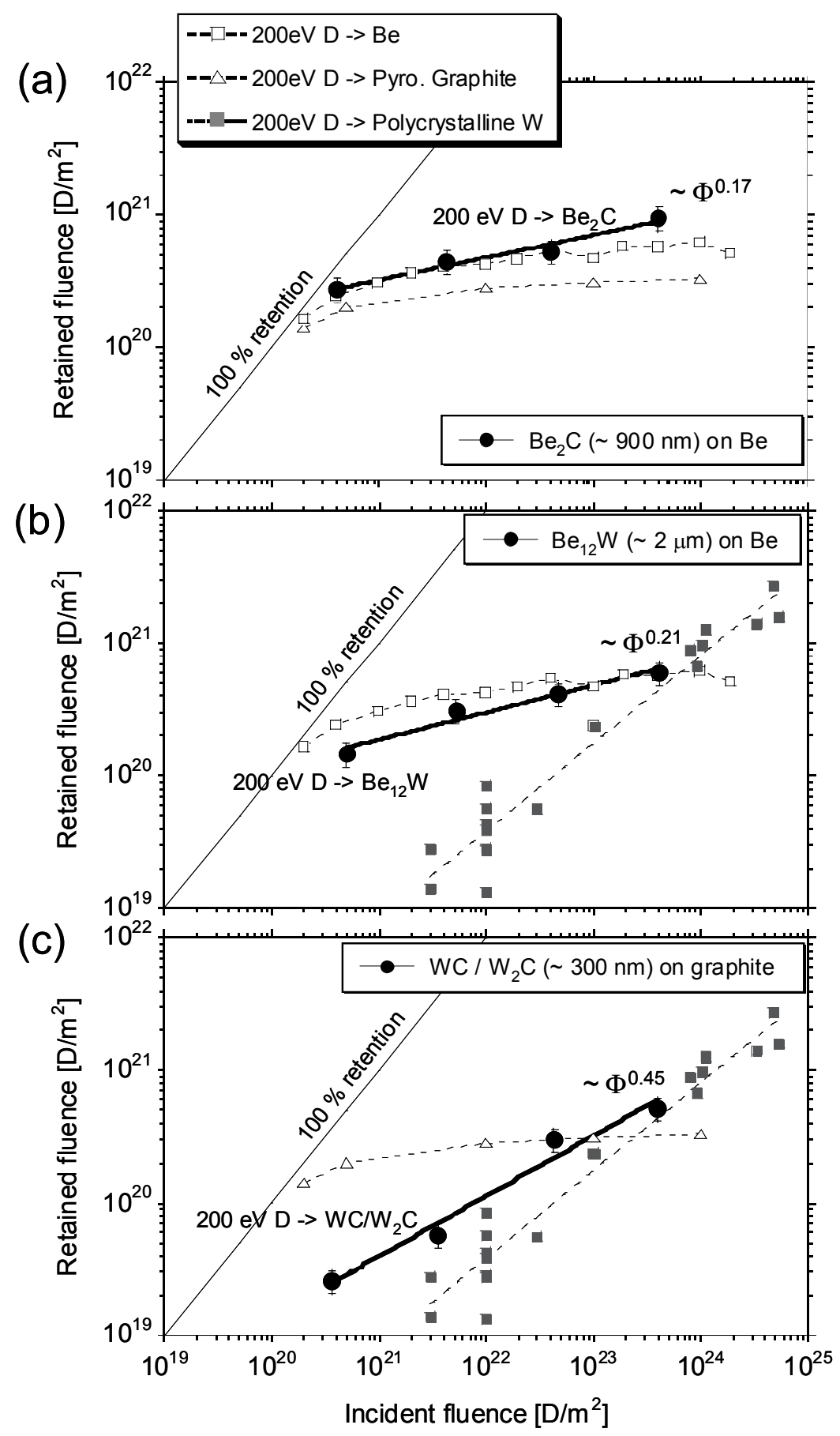

Fig.2 


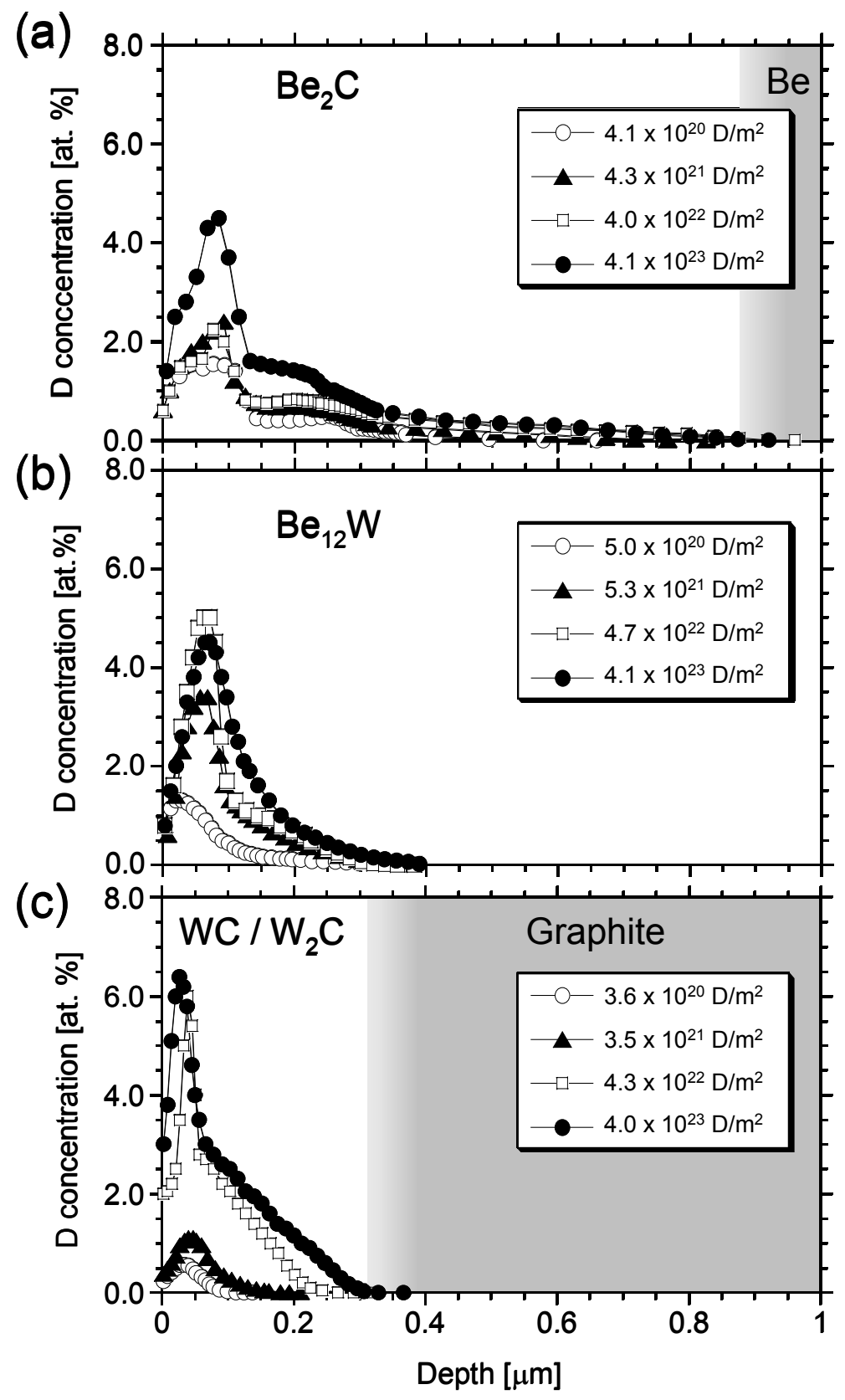

Fig. 3 